\title{
Pengembangan Media Berbasis Hologram 3D Dalam Pembelajaran Tanaman Kelapa
}

\author{
Fauziah Eka Safitri1), Djuniadii ${ }^{2}$ \\ 1) 2) Program Studi Pendidikan Teknik Informatika dan Komputer, Universitas Negeri Semarang \\ fauziahekasafitri.x1a2.10@gmail.com
}

\begin{abstract}
In recent years, the application and development of $3 D$ hologram technology expanded in many areas, including to develop learning media. This research aimed at knowing the development, feasibility, effectiveness, practicability of usefulness and easiness of $3 D$ hologram-based learning media on coconut plant theme lesson. The research has been carried out at kindergarten education with a sample of 24 students from TK Islam Al Madina Semarang. The method used is $R \& D$ with ADDIE development model, there are Analysis, Design, Development, Implementation, and Evaluation. The result reported that: the media $3 D$ hologram for learning coconut plant has been developed by obtaining input from validator media and validator material, the developed media was considered feasible based on the media validator's assessment with score of $87 \%$ and the validator's material with a score of $80 \%$, the developed media was effective, evidenced by mean score of post-test student's answers was 99,3, which is increase 24\% compared to the pre-test 75; and the developed media was considered useful and easy to use by teacher and parents with their respective scores $82 \%$ and $92 \%$. The overall result shows that the developed media hologram is feasible, effective, useful, and easy as a learning media.
\end{abstract}

Keywords: $3 D$ hologram, learning media, Coconut plant, ADDIE model

(c) (i) This is an open access article distributed under the Creative Commons 4.0 Attribution License, which permits unrestricted use, distribution, and reproduction in any medium, provided the original work is properly cited. @2018 by author and Universitas Negeri Padang.

\section{PENDAHULUAN}

Beberapa tahun terakhir, teknologi hologram 3D telah digunakan dalam komuni kasi, pelatihan militer, hiburan, augmented reality virtual, dan pelatihan medis (Lee, 2013). Menurut Lee, meskipun teknologi hologram banyak dikembangkan dan digunakan di luar lingkungan pendidikan, namun tetap terdapat potensi. Salah satunya dalam pengembangan media pembelajaran di ruang kelas untuk menarik perhatian siswa dan membuat pembe lajaran lebih menyenangkan dan berkesan (Salih, Sulaiman, M., \& Rahmat, 2017). Inovasi dalam media pembelajaran ini membantu guru untuk memotivasi dan melibatkan siswa dalam pembelajarannya (Hoon \& Shaharuddin, 2019).

Pengertian media menurut Geralch dan Elly adalah segala sesuatu yang menunjang siswa mampu memperoleh pengatahuan, keterampilan, atau sikap. Contohnya manusia, materi, atau kejadian (Arsyad, 2016). Menurut Latuheru, media pembelajaran merupakan alat komunikasi dari guru untuk menyampaikan materi pembelajaran kepada siswa (Kemen dikbud, 2016). Dari kutipan dapat disimpulkan bawah media pembelajaran adalah suatu metode yang sengaja dirancang dalam proses belajar mengajar agar siswa mencapai tujuan pembe lajaran secara efektif. Beberapa peneliti yang meneliti tentang penggunaan media dalam pembelajaran menyimpulkan, ada perbedaan signifikan antara hasil belajar siswa yang menggunakan media dengan tanpa media. Ini menunjukkan pentingnya penggunaan media. (Guslinda \& Kurnia, 2018).

Media pembelajaran dikelompokkan men jadi beberapa jenis dan ragam. Dari yang paling sederhana, murah, canggih hingga mahal. Dalam prakteknya ada media buatan guru sendiri, namun terdapat juga buatan pabrik. Terdapat media yang disediakan oleh alam dan bisa digunakan langsung, namun ada media yang secara spesifik dibuat untuk kebutuhan pembelajaran (Kemendikbud, 2016). Demikian, terkadang guru memiliki kendala dalam menyi apkan media pembelajaran, diantaranya: media terlalu besar, berbahaya, mudah rusak, dan mahal sehingga sulit untuk dibawa kemanamana (Arifuddin, Kuswandi, \& Soepriyanto, 2019). Hal ini senada dengan pendapat Edgar Dale bahwa "kejadian-kejadian, atau bendabenda yang sebenarnya sulit diperoleh, mungkin juga terlampau besar untuk dibawa ke dalam kelas, atau terlampau terlalu jauh maka dapat 
dibuat benda tiruan yang rupanya sama dengan bentuk sebenarnya hanya ukurannya mungkin tidak sama" (Kemendikbud, 2016).

Berdasarkan wawancara yang dilakukan kepada seorang guru TK Islam Al Madina bidang kurikulum, salah satu tema pembelajaran untuk anak kelas B yang cukup sulit dibuatkan medianya adalah tanaman kelapa. Sebab tanaman kelapa cukup sulit dijumpai di wilayah Semarang Barat, sehingga siswa tidak dapat mengamatinya bentuk dan warna dari bagianbagian tanaman kelapa secara langsung, terlebih di masa pandemi seperti ini dimana setiap sekolah melaksanakan BDR (Belajar Dari Rumah). Selain itu, konsentrasi anak-anak TK juga lebih minim daripada anak-anak di jenjang pendidikan yang lebih tinggi. Mereka mudah bosan dalam menerima pembelajaran. Maulana \& Hardiansyah (2017) berpendapat, anak-anak lebih senang melihat gambar dan animasi daripada mendengarkan penjelasan guru. Terle bih dalam generasi digital native ini anak-anak telah mengenal gadget, seperti tablet dan smartphone dan menyebabkan mereka lebih senang belajar dengan perangkat digital daripada belajar melalui buku. Teknologi hologram dapat menjadi salah satu alternatif dalam pembuatan media pembelajaran berupa tiruan obyek 3 dimensi yang dapat menampilkan ukuran tinggi, panjang, dan lebar dari suatu benda dan dapat diamati dari sisi depan, belakang, maupun samping (Soepriyanto, Sikhabuden, \& Surah man, 2018).

Hologram merupakan salah satu produk dari holografi. Menurut Rudiansyah dalam (Tawaqqal, Ningrum, \& Yamin, 2017), teknologi hologram dihasilkan melalui perpadu an dua sinar yang koheren dan berbentuk mikroskopik. Di dalam hologram terdapat sekumpulan informasi optik pembentuk objekobjek 3D yang dapat berupa suatu gambar, pemandangan, atau animasi. Secara umum hologram dibagi menjadi dua, yaitu hologram transmisi dan refleksi. Dikatakan hologram transmisi karena bayangan didapat dengan cara menstransmiskan cahaya rekontruksi. Hal ini berbeda dengan hologram refleksi, yang mana bayangannya didapat dengan cara merefleksikan cahaya rekontruksi (Handani, Saputra, \& Sari, 2017).

Rancangan reflektor 3D hologram refleksi dapat berupa piramida hologram yang terbuat dari kaca, mika, atau akrilik yang disusun seperti piramida terpotong puncaknya (Roslan \& Ahmad, 2017). Piramida hologram merupakan reflektor berbentuk prisma yang memungkinkan pengamat untuk mengamati objek 3D yang dihasilkan komputer dari perspektif yang berbeda melalui segala sisi prisma (Muhammad, Ismail, \& Sunar, 2016). Secara teknis, ini bukanlah hologram sesungguhnya, melainkan memberikan kesan hologram (Siang et al., 2018). Greenslade (dikutip di Handani et al., 2017) mengatakan bahwa metode ini diawali dengan penemuan The Papper's Ghost Illusion Technique yang memanfaatkan sifat pantul pada cermin dalam seni panggung.

Beberapa penelitian tentang penggunaan 3D hologram sebagai media pembelajaran telah dilakukan. Fuadi \& Listyorini (2018) dalam penelitiannya telah menghasilkan media pembelajaran 3D hologram pengenalan sistem tata surya. Dengan media ini, masyarakat umum lebih antusias untuk mempelajari sistem tata surya. Namun dalam penelitian ini tidak dijelaskan secara spesifik pengaruh penggunaan media 3D hologram terhadap hasil belajar siswa dalam pembelajaran maupun analisis kepraktis an pengguna media. Penelitian lain dilakukan oleh Orcos, Jordán, \& Magreñán (2019) dengan judul "3D Visualization through the Hologram for the Learning of Area and Volume Concepts". Menghasilkan media 3D hologram pembelajaran volume dan luas bangun ruang untuk anak SD kelas 3. Berdasarkan analisis hasil pre-test dan post-test, hasil belajar siswa yang menggunakan media ini lebih tinggi daripada siswa yang belajar secara tradisional. Namun dalam peneliti an ini belum dilakukan analisis kepraktisan pengguna media. Kemudian Sari (2020) melaku kan penelitian berjudul "Penerapan Media Hologram 3D Smartphone dan Media Gambar Untuk Peningkatan Kecerdasan Visual Spasial Anak Usia 5-6 Tahun di KB-TK Islam Al Azhar 22 Semarang" telah membandingkan pembelajar an yang menggunakan media hologram 3D dengan media gambar. Hasilnya kecerdasan visual spasial anak yang belajar menggunakan 3D hologram lebih besar $26,58 \%$ dibanding yang belajar menggunakan media gambar. Namun dalam penelitian ini belum dilakukan analisis kepraktisan pengguna media.

Berdasarkan penelitian-penelitian tersebut dan hasil analisis kebutuhan di TK Islam AlMadina Semarang, penulis bertujuan ingin mengembangkan sebuah media pembelajaran 
3D hologram untuk pembelajaran tanaman kelapa yang layak menurut ahli, praktis digunakan oleh pengguna, serta efektif dalam meningkatkan hasil belajar siswa kelas B. Reflektor hologram yang digunakan berbentuk piramida terbalik terpotong puncaknya yang terbuat dari lembaran mika bening. Sementara video hologram 4 sisi direfleksikan dari layar smartphone atau tablet yang diatur sesuai ketentuan penempatan objek.

\section{METODE PENELITIAN}

Metode yang digunakan dalam penelitian ini adalah $R \& D$ dengan model pengembangan ADDIE, yaitu Analysis, Design, Development, and Implementation. Subjek uji coba adalah 24 siswa kelas B, 24 orang tua siswa dan 1 guru kelas di TK Islam Al-Madina Kota Semarang untuk memperoleh penilaian kepraktisan terha dap kemanfaatan dan kemudahan penggunaan media.

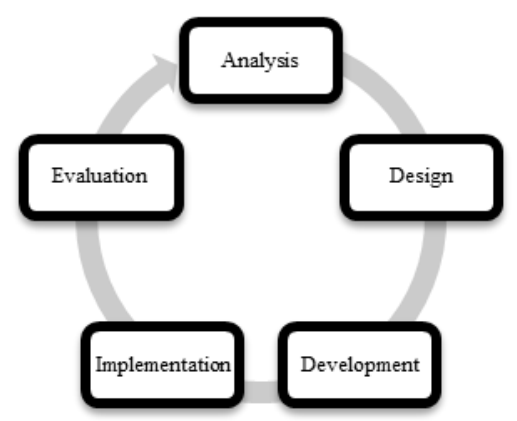

Gambar 1. Diagram pengembangan ADDIE

Pada proses anilisis (analysis) dilakukan analisis kerja dan analisis kebutuhan dengan menetapkan kondisi saat ini, kondisi yang diinginkan, serta jenis masalah yang muncul dari kebutuhan (Arifudin, Koeswandi, dan Soepri yanto, 2019:12). Analisis ini diperoleh melalui wawancara langsung dengan guru bidang kurikulum TK Islam Al-Madina Semarang. Dari hasil wawancara diperoleh, sebuah media pembe lajaran diperlukan untuk menunjang belajar dari rumah (bdr) di masa pandemi ini yang berarti media perlu dibawa ke rumah. Mengingat objek tanaman kelapa tidak memungkinkan untuk dihadapkan dan dipelajari oleh siswa secara langsung, maka dibuatkan media tiruannya dengan memanfaatkan media hologram.
Tabel 1. Analisis Kebutuhan

\begin{tabular}{ll}
\hline Judul & $\begin{array}{l}\text { 3D Hologram Pengenalan } \\
\text { Tanaman Kelapa }\end{array}$ \\
\hline Tujuan & $\begin{array}{l}\text { Siswa mampu mengenal nama, } \\
\text { bentuk, ukuran, dan ciri-ciri dari } \\
\text { tanaman kelapa dan bagian- } \\
\text { bagiannya. }\end{array}$
\end{tabular}

Siswa mampu menunjuk, mengeja dan menulis sendiri huruf-huruf dari bagian-bagian tanaman.

Siswa mengetahui manfaat dari bagian-bagian tanaman kelapa.

Siswa mampu menyebu dan menjodohkan contoh benda hasil olahan dari bagian-bagian tanaman kelapa.

\begin{tabular}{ll}
\hline Pengguna & Guru, Orang Tua, Siswa. \\
\hline Animation & Animasi hologram 3D tanaman \\
& kelapa, daun, bunga, buah, \\
& batang, dan akar beserta audio \\
& penjelasannya, game tebak \\
& gambar dengan drag and drop, \\
& game menjodohkan gambar \\
& dengan linked game, dan game \\
& tebak kata dengan puzzle \\
& sederhana.
\end{tabular}

Object Tanaman kelapa: akar, batang, daun, bunga, buah (muda, tua, batok, serabut); benda-benda hasil dari setiap bagian tanaman.
Interactivity Terdapat menu bagian tanaman kelap, menu video hologram, menu kuis, menu panduan, menu tentang, tombol keluar.

Tahap perancangan (design) yang dilaku kan adalah: (1) merancang materi yang ditampilkan dalam media, (2) pembuatan flowchart yang menggambarkan program, (3) pembuatan navigasi aplikasi sebagai perencana an alur program, (4) pengumpulan bahan ajar/materi berupa gambar, animasi, audio, video, dan lain sebagainya untuk menunjang pembuatan media, (5) perancangan 3D dan animasi dari bagian-bagian tanaman kelapa; dan dan (6) penyusunan acuan tes (pre-test dan post- 
test). Berikut ini struktur navigasi dan flowchart aplikasi holoco.

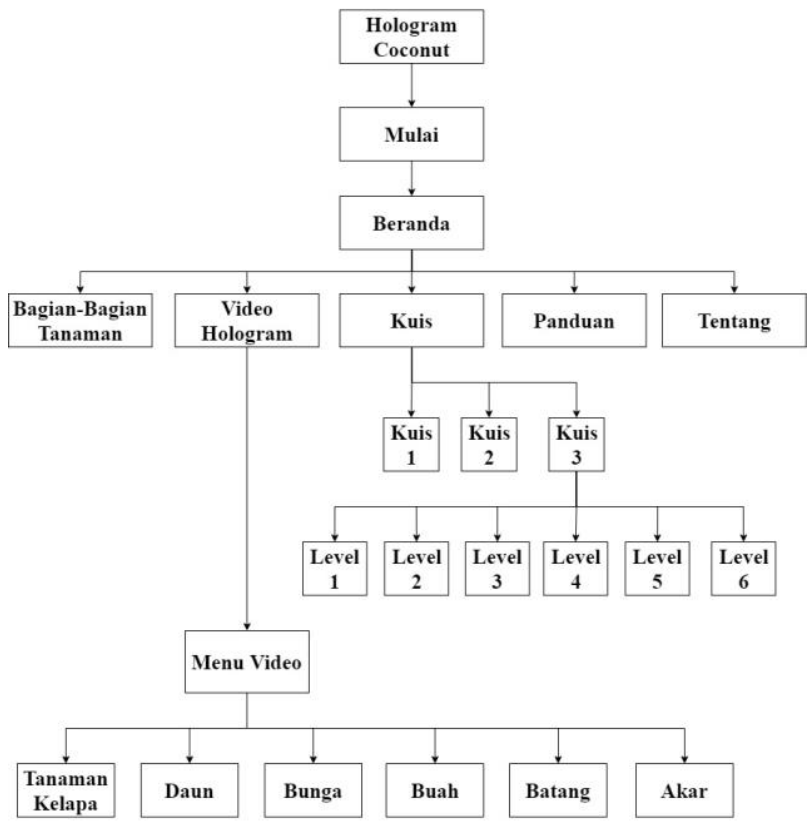

Gambar 2. Struktur Navigasi Holoco

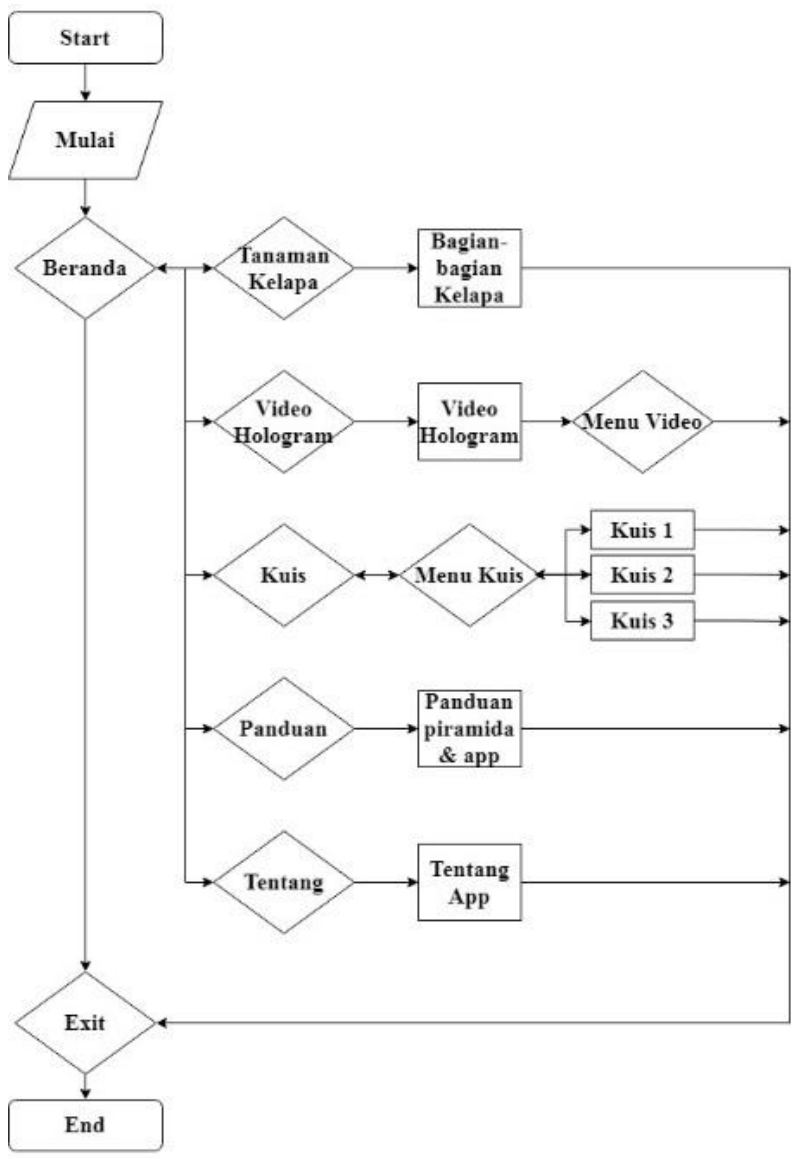

Gambar 3. Flowchart Aplikasi Holoco

Tahap pengembangan (development) dila kukan: (1) pembuatan animasi dan model 3D dari tanaman kelapa dan bagian-bagiannya menggunakan software paint $3 d$, (2) pembuatan video hologram 4 sisi dengan software camtasia, (3) pembuatan aplikasi android sesuai desain dalam tahap sebelumnya menggunakan software adobe animate $c c$, (4) pembuatan piramida hologram dari mika bening.

Tahap implementasi (implementation) melakukan: (1) uji validasi media kepada seorang validator media dan seorang validator materi, (2) perbaikan media sesuai saran validator materi dan media, (3) distribusi media, (4) uji coba penggunaan media oleh guru, siswa bersama orang tua siswa.

Tahap evaluasi (evaluation) penulis mela kukan: (1) penentuan kriteria evaluasi, (2) pemilihan alat evaluasi yaitu perhitungan data dari instrument angket yang telah dibuat, (3) analisa kelayakan media, (4) analisa kepraktisan media terhadap kemanfataan dan kemudahan pengguna, (5) analisa efektivitas media.

Metode pengumpulan data dilakukan dengan cara studi pustaka, observasi, wawancara, dan angket. Sementara instrumen pengumpulan datanya berupa: soal pre-test dan post-test, angket kelayakan ahli media dan ahli materi, dan angket kepraktisan pengguna terhadap kemanfaatan dan kemudahan media oleh guru dan orang tua murid. Orang tua menggantikan murid dikarenakan terbatasnya kemampun anak tk dalam melakukan pengsisian angket

Data hasil penelitian dianalisis secara kualitatif dan kuantitatif. Data kualitatif diper oleh dari kritik, komentar atau saran untuk memperbaiki kualitas media, sedangkan data kuantitatif diperoleh dari penilaian angket menggunakan skala perhitungan Likert dengan 5 titik respon pilihan, kemudian dihitung persen tase rata-rata untuk menentukan kriteria: 1) kelayakan media dan 2) penilaian kemanfaatan dan kemudahan oleh guru dan orang tua.

Pengubahan data kuantitatif ke kualitatif dalam uji kelayakan media dan penilaian kemanfaatan dan kemudahan oleh pengguna (guru dan orang tua) menurut Riduwan dalam (Dwi \& Zona, 2020) mempunyai rentang nilai "5 - 1" dengan kriteria "Sangat layak/Sangat setuju - Sangat tidak layak/Sangat tidak setuju".

Perhitungan presentase kelayakannya digunakan rumus 1 (Riduwan dikutip di Dwi \& Zona, 2020), sedangkan penentuan peningkatan hasil belajar siswa dilakukan dengan Norma lized Gain Score yang perhitungannya dijelas 
kan pada rumus 2 (Wiyono dikutip di Putra, Supraptono, \& Wibowo, 2016).

$$
\begin{aligned}
& \text { Presentase }=\frac{\text { skor yang diperoleh }}{\text { skor ideal maksimal }} \times 100 \%(1) \\
& N \text {-gain }=\frac{\text { skorpretest }- \text { skorposttest }}{\text { skormaksimum }- \text { skorpretst }}(2)
\end{aligned}
$$

Media pembelajaran dikatakan layak, berrnanfaat dan mudah apabila semua aspek dalam lembar validasi ahli dan angket respon guru maupun orang tua mencapai lebih dari $61 \%$ dengan kriteria layak/setuju maupun sangat layak/sangat setuju.

Kemudian untuk mengetahui tingkat efektivitas media, dilakukan analisis terhadap data hasil pre-test dan post-test siswa melalui normalized gain score. Dimana pembagian kategori perolehan $\mathrm{N}$-gain dalam persen (\%) dapat mengacu pada tabel di bawah ini.

Tabel 2. Kategori Tafsiran Efektivitas N-gain

\begin{tabular}{cc}
\hline Presentase (\%) & Tafsiran \\
\hline$<40$ & Tidak Efektif \\
\hline $40-55$ & Kurang Efektif \\
\hline $56-75$ & Cukup Efektif \\
\hline$>76$ & Efektif \\
\hline & Sumber: Hake, R.R, 1999
\end{tabular}

\section{HASIL DAN PEMBAHASAN}

Hasil produk penelitian ini berupa media pembelajaran berbasis hologram 3D yang terdiri dari dua bagian, yakni (1) aplikasi android bernama holoco (hologram coconut) yang di dalamnya berisi materi, kuis dan video hologram pembelajaran tanaman kelapa; dan (2) piramida hologram yang terbuat dari mika rigid $(P V C)$ setebal $0,30 \mathrm{~mm}$.

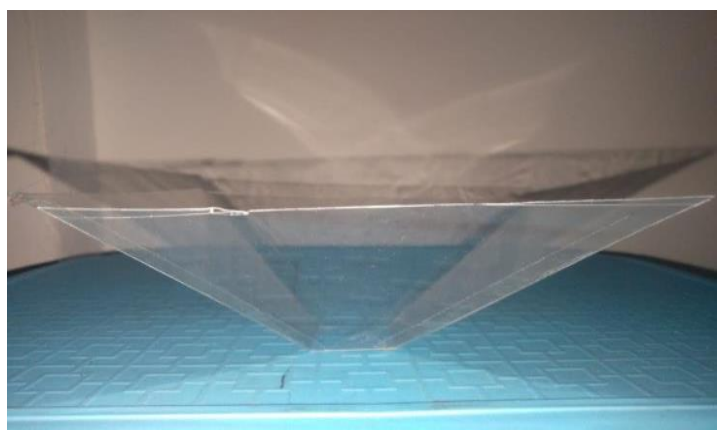

Gambar 4. Piramida Hologram

Aplikasi holoco dikembangkan mengguna kan software Adobe Animate CC, Adobe Photoshop, Canva dan software pendukung lainnya. Media pembelajaran ini digunakan untuk membantu siswa kelas B di TK Islam AlMadina Semrang dalam mempelajari materi tema tanaman kelapa, sub tema bagian dan manfaat tanaman kelapa.

Aplikasi ini disajikan dalam beberapa menu, yaitu: (1) menu bagian tanaman kelapan berisi gambar tanaman kelapa dan bagianbagiannya, (2) menu video hologram berisi 6 video hologram 4 sisi, yaitu video tanaman kelapa, daun, bunga, buah, batang, dan akar beserta penjelasan tentang manfaat dari masingmasing bagian tanaman, (3) menu kuis berisi 3 kuis, yakni kuis menebak gambar, menjodohkan gambar, dan tebak kata, (4) menu panduan berisi tutorial pembuatan piramida hologram dan penggunaan aplikasi, (5) menu aplikasi berisi informasi dan pengembang aplikasi. Berikut tampilan aplikasi, video hologram 4 sisi, dan objek 3D tertampil tampak depan.

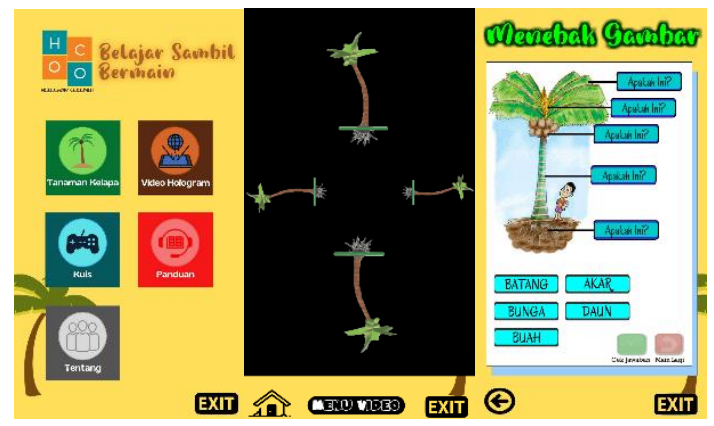

Gambar 5. Tampilan Aplikasi

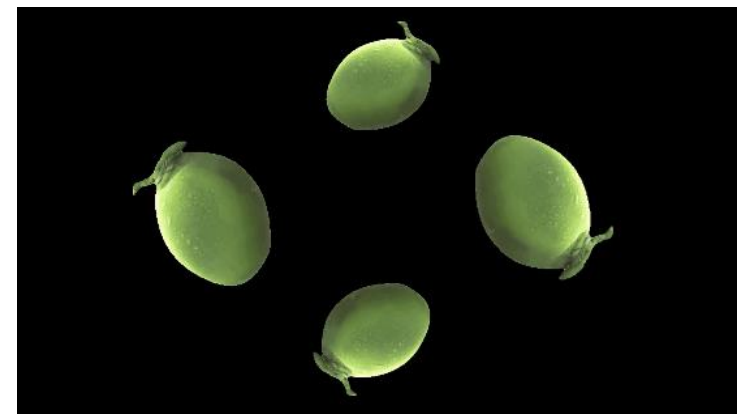

Gambar 6. Tampilan Video Hologram 4 Sisi

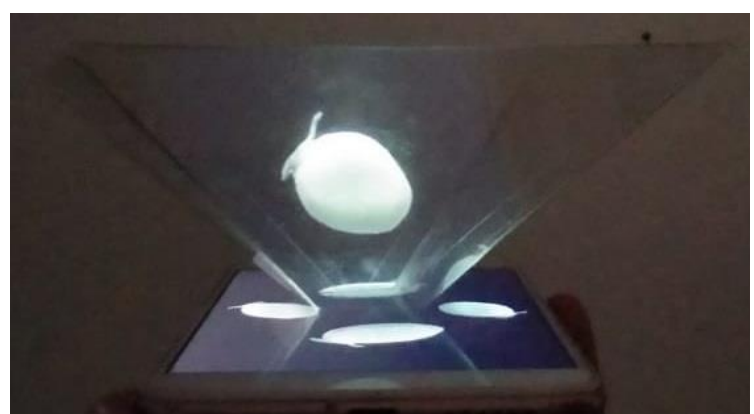

Gambar 7. Objek 3D Tertampil Tampak Depan 
Uji kelayakan media dilakukan untuk mengukur kualitas media dan materi yang dikembangkan. Data kelayakan media diperoleh melalui penilaian seorang validator media dan seorang validator materi melalui angket. Parameter untuk mengukur kualitas kelayakan media terdiri dari 4 aspek yaitu (1) rekayasa perangkat lunak, (2) kebahasaan, (3) sajian, dan (4) grafis. Sementara parameter untuk mengukur kualitas kelayakan materi terdiri dari 3 aspek, (1) desain pembelajaran, (2) rekayasa perangkat lunak, dan (3) tampilan visual (Wahono, 2006; Dikmenum, 2008). Hasil penilaian kemanfaatan dan kemudahan penggunaan media diperoleh dari pengisian angket oleh seorang guru kelas dan sejumlah orang tua siswa. Kemudian efektivitas medianya dianalisi dengan menghi tung nilai pre-test dan post-test siswa.

Berdasarkan hasil uji validitas media oleh ahli media diperoleh presentase keseluruhan yaitu $87 \%$. Pada tabel 4 ditunjukkan beberapa saran dan masukan dari validator media. Perbaikan dilakukan agar pengguna tahu dengan tujuan pembelajaran, maksud aplikasi ini, dan agar pengguna lebih mudah dalam memahami cara penggunaan media.

Tabel 4. Masukan Ahli Media

\begin{tabular}{ll}
\hline \multicolumn{1}{c}{ Saran } & \multicolumn{1}{c}{ Perbaikan } \\
\hline Penambahan tujuan & Tujuan dan profil \\
dan profil aplikasi & $\begin{array}{l}\text { aplikasi ditambahkan } \\
\text { di menu tentang }\end{array}$ \\
Panduan penggunaan & Panduan media \\
media kurang & dilengkapi, tidak \\
lengkap, terlalu cepat & terlalu cepat, dan \\
dan diberikan audio & ditambahkan audio \\
penjelasan & penjelasan \\
\hline
\end{tabular}

Tabel 5 menunjukkan data hasil analisis tiap aspek terhadap angket dari validator ahli media, skor rata-rata yang didapatkan adalah 87 dari skor maksimal 100. Berdasarkan hasil perhitungan yang diperoleh, maka media yang dikembangkan sangat layak untuk diujicobakan di sekolah.

Tabel 5. Hasil Validasi Ahli Media

\begin{tabular}{llcl}
\hline \multicolumn{1}{c}{ Aspek } & Skor & \% & Kriteria \\
\hline $\begin{array}{l}\text { Rekayasa } \\
\text { Perangkat Lunak }\end{array}$ & 30 & $86 \%$ & $\begin{array}{l}\text { Sangat } \\
\text { layak }\end{array}$ \\
\hline Kebahasaan & 18 & $90 \%$ & $\begin{array}{l}\text { Sangat } \\
\text { layak }\end{array}$ \\
\hline Sajian & 17 & $85 \%$ & $\begin{array}{l}\text { Sangat } \\
\text { layak }\end{array}$ \\
\hline
\end{tabular}

\begin{tabular}{llll}
\hline Grafis & 22 & $88 \%$ & $\begin{array}{l}\text { Sangat } \\
\text { layak }\end{array}$ \\
\hline
\end{tabular}

Hasil uji validitas materi oleh validator materi, diperoleh presentase keseluruhan $80 \%$. Tabel 6 menunjukkan beberapa saran dan masukan. Perbaikan ini dilakukan agar anak dapat melihat bagian-bagian dari daun kelapa yang ditunjukkan. Sementara saran pembuatan piramida hologram yang lebih kokoh tidak dilakukan karena keterbatasan biaya dan waktu.

Tabel 6. Masukan Ahli Materi

\begin{tabular}{|c|c|}
\hline Saran & Perbaikan \\
\hline $\begin{array}{l}\text { Pada video hologram, } \\
\text { nama bagian-bagian } \\
\text { daun kelapa tidak } \\
\text { ditunjukkan dengan } \\
\text { jelas }\end{array}$ & $\begin{array}{l}\text { Nama-nama bagian } \\
\text { daun kelapa } \\
\text { ditunjukkan dengan } \\
\text { jelas dilengkapi } \\
\text { penjelasan audio }\end{array}$ \\
\hline $\begin{array}{l}\text { Piramida hologram } \\
\text { kurang kokoh dan } \\
\text { mudah bergeser } \\
\text { posisinya }\end{array}$ & - \\
\hline
\end{tabular}

Tabel 7 menunjukkan data hasil analisis tiap aspek terhadap angket validasi materi oleh ahli materi, skor keseluruhan yang didapatkan adalah 80 dari skor maksimal 100. Berdasarkan hasil perhitungan diperoleh presentase kevalidan produk yaitu $80 \%$ yang dikategorikan layak. Make materi layak untuk diujicobakan di sekolah.

Tabel 7. Hasil validasi ahli media

\begin{tabular}{llcl}
\hline \multicolumn{1}{c}{ Aspek } & Skor & \% & Kriteria \\
\hline $\begin{array}{l}\text { Desain } \\
\text { pembelajaran }\end{array}$ & 40 & $80 \%$ & Layak \\
\hline $\begin{array}{l}\text { Rekayasa Perangkat } \\
\text { Lunak }\end{array}$ & 16 & $80 \%$ & Layak \\
\hline Tampilan visual & 16 & $80 \%$ & Layak \\
\hline
\end{tabular}

Uji kepraktisan terhadap kemanfaatan dan kemudahan media dilakukan dengan memberikan media yang telah divalidasi oleh ahli media dan materi serta angket penilaian kepada salah seorang guru kelas B dan 24 orang tua siswa kelas B di TK Islam Al-Madina Semarang. 


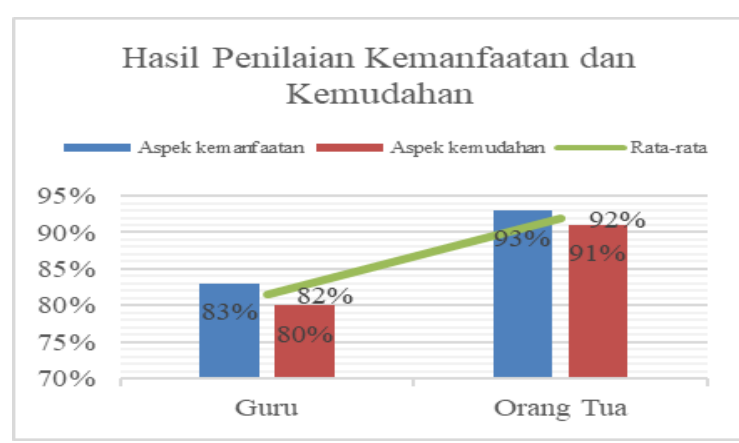

Gambar 9. Hasil Penilaian Kemanfaatan dan Kemudahan

Hasil analisis terhadap angket guru dan orang tua dapat dilihat pada gambar 9. Dari 2 aspek yang dinilai yaitu aspek kemanfaatan dan kemudahan penilaian oleh guru diperoleh total skor sebanyak 41 dari skor maksimal 50 dengan rata-rata nilai presentase sebesar $82 \%$. Kemudian hasil analisis terhadap penilaian 24 orang tua siswa diperoleh skor keseluruhan dari sebanyak 1102 dari skor maksimal 1200 dengan rata-rata nilai presentase $92 \%$. Hal ini menunjuk kan bahwa media ini dikategorikan sangat ber manfaat dan mudah digunakan oleh pengguna.

Tabel 8. Hasil Analisis Statistik Deskriptif

\begin{tabular}{lcc}
\hline & Pre-test & Post-test \\
\hline Jumlah siswa & 24 & 24 \\
\hline Rata-rata & 75 & 99.3 \\
\hline Nilai tertinggi & 100 & 100 \\
\hline Nilai terendah & 0 & 0 \\
\hline Median & 100 & 100 \\
\hline Rentang & 100 & 100 \\
\hline Varian & 1604.48 & 12.98 \\
\hline Standar deviasi & 40.06 & 3.60 \\
\hline
\end{tabular}

Tabel 8 menjelaskan parameter nilai terendah dan tertinggi, rata-rata, median, rentang, varian dan standar deviasi hasil pre-test dan post-test 24 siswa kelas B di TK Islam AlMadina Semarang. Nilai terendah dan tertinggi untuk masing-masing pre-test dan post-test sama, yaitu 0 dan 100. Nilai rata-rata, varian, dan standar deviasi untuk pre-test masingmasing 75, 1604.48, dan 40.6, sedangkan nilai rata-rata, varian, dan standar deviasi untuk posttest masing-masing adalah 99.3, 12.98, dan 3.60.

Berdasarkan analisis statistik deskriptif yang dilakukan, dinyatakan bahwa nilai rata-rata post-test lebih tinggi dibanding nilai rata-rata pre-test. Kemudian berdasarkan perhitungan Normalized Gain Score, peningkatan hasil belajar siswa setelah uji coba produk didapatkan hasil 0,975 atau $97.5 \%$. Hasil tersebut menunjukkan bahwa penggunaan media yang Volume 5| Nomor 1|Mei 2021|Page 87-94 dikembangkan termasuk dalam kategori efektif meningkatkan hasil belajar siswa.

\section{KESIMPULAN}

Media pembelajaran berbasis hologram 3D yang telah dikembangkan berupa aplikasi android dengan proyektor piramida hologram pada materi pengenalan dan manfaat bagianbagian tanaman kelapa untuk anak TK. Aplikasi dikembangkan dengan software adobe animate $c c$ dan software pendukung lainnya meng gunakan model pengembangan ADDIE yaitu, Analysis, Design, Development, Implementation, and Evaluation.

Berdasarkan penilaian ahli media dan ahli materi, media hologram 3D yang dikembangkan layak untuk diuji cobakan untuk pembelajaran dengan persentase penilaian masing-masing ahli adalah $87 \%$ dan $80 \%$. Kemudian hasil angket respon kepraktisan guru dan orang tua terhadap kemanfaatan dan kemudahan media masingmasing diperoleh nilai sebesar $82 \%$ dan $92 \%$. Hal ini menunjukkan bahwa media hologram 3D praktis digunakan oleh pengguna dalam proses belajar mengajar.

Kemudian berdasarkan uji coba diperoleh nilai pre-test siswa sebesar 75 dan nilai post-test 99.3, menunjukkan bahwa kemampuan siswa dalam memahami materi tentang bagian dan manfaat tanaman kelapa mengalami pening katan. Dari perhitungan N-Gain dapat dikatakan bahwa media efektif meningkatkan hasil belajar siswa. Dengan demikian, media pembelajaran tanaman kelapa berbasis hologram 3D yang dikembangkan layak, efektif, mudah dan ber manfaat bagi siswa, guru, maupun orang tua di TK Islam Al Madina Kota Semarang.

\section{DAFTAR PUSTAKA}

Arifuddin, A., Kuswandi, D., \& Soepriyanto, Y. (2019). Pengembangan Media Obyek 3 Dimensi Digital Sel Hewan dan Tumbuhan Memanfaatkan Piramida hologram Untuk MTS. JKTP Jurnal Kajian Teknologi Pendidikan, 2(1), 9-15.

Arsyad, A. (2016). Media Pembelajaran. Jakarta: Raja Grafindo Persada.

Dwi, A., \& Zona, R. (2020). Desain dan Uji Coba Media Pembelajaran Video Animasi Stop Motion Berbasis Saintifik Pada Materi Ikatan Kimia ( Desain dan Uji 
Coba Media Pembelajaran Video Animasi Stop Motion .........) JEP | Volume 4 | Nomor 2 | November 2020 | Page 122-129. 4(November).

Fuadi, M. M., \& Listyorini, T. (2018). 3D hologram introduction of solar system based on android. AIP Conference Proceedings, 1977(030009). https://doi.org/10.1063/1.5042928

Guslinda, \& Kurnia, R. (2018). Media Pembelajaran Anak Usia Dini. In Media Pembelajaran. Surabaya: CV. Jakad Publishing Surabaya.

Handani, S. W., Saputra, D. I. S., \& Sari, F. N. (2017). Desain Piramida 3D Holographic Reflection Sebagai Bentuk Visualisasi Bangunan. Citisee, 1, 105-108.

Hoon, L. N., \& Shaharuddin, S. S. (2019). Learning Effectiveness of 3D Hologram Animation on Primary School Learners. Journal of Visual Art and Design, 11(2), 93-104.

https://doi.org/10.5614/j.vad.2019.11.2.2

Kemendikbud. (2016). Strategi Pemanfaatan Media Pembelajaran. In T. P. Pegawai (Ed.), Pusdiklat Pegawai Kemendikbud. Depok: Pusdiklat Pegawai Kemendikbud.

Lee, H. (2013). 3D Holographic Technology and Its Educational Potential. TechTrends, 57(4), 34-39. https://doi.org/10.1007/s11528-013-0675-8

Maulana, M. S., \& Hardiansyah, A. M. F. (2017). Media Pembelajaran Pengenalan Hewan-Hewan Khas Kalimantan Berbasis Android Mobile Learning (Studi Kasus: TK Aisyiyah Bustanul Athfal 5) Muhammad. Jurnal Khatulistiwa Informatika, 5(2), 119-127.

Muhammad, A. B. A., Ismail, N. A. F., \& Sunar, M. S. (2016). Reflective Prism Display Using Pepper's Ghost Technique Software Toolkit Plugin for Unity 3D. Jurnal Teknologi, 78(12-3), 189-196. Retrieved from www.jurnalteknologi.utm.my

Orcos, L., Jordán, C., \& Magreñán, A. (2019). 3D Visualization through the Hologram for the Learning of Area and Volume Concepts. Mathematics, 7(3), 1-20. https://doi.org/10.3390/math7030247

Volume 5| Nomor 1|Mei 2021|Page 87-94
Putra, R. P. R., Supraptono, E., \& Wibowo, H. (2016). Modul Belajar Elektronik pada Materi Ajar Merakit Personal Computer. Edu Komputika Journal, 3(1), 40-48. https://doi.org/10.15294/edukomputika

Roslan, R. K., \& Ahmad, A. (2017). 3D Spatial Visualisation Skills Training Application for School Students Using Hologram Pyramid. International Journal on Informatics Visualization, 1(4), 170-174. https://doi.org/10.30630/joiv.1.4.61

Salih, S. Q. M., Sulaiman, P. S., M., R., \& Rahmat, R. W. O. K. (2017). 3D Holographic Rendering For Medical Images Using Manipulates Lighting in a 3D Pyramid Display. Journal of Advanced Science and Engineering Research, 7(June), 14-26. Retrieved from http://www.sign-ific-

ance.co.uk/index.php/JASER/article/view/ 1576

Sari, N. (2020). Penerapan Media Hologram 3D Smartphone dan Media Gambar Untuk Peningkatan Kecerdasan Visual Spasial Anak Usia 5-6 Tahun di KB-TK Islam Al Azhar 22 Semarang. Universitas Negeri Semarang.

Siang, C. V., Isham, M. I. M., Mohamed, F., Yusoff, Y. A., Mokhtar, M. K., Tomi, B., \& Selamat, A. (2018). Interactive holographic application using augmented reality EduCard and 3D holographic pyramid for interactive and immersive learning. 2017 IEEE Conference on ELearning, e-Management and e-Services, IC3e 2017, 73-78. https://doi.org/10.1109/IC3e.2017.8409241

Soepriyanto, Y., Sikhabuden, \& Surahman, E. (2018). Pengembangan Obyek 3D Digital Pada Meja Piramida Hologram Untuk Pembelajaran Kelas. Jurnal Kajian Teknologi Pendidikan, 1(4), 333-339.

Tawaqqal, I., Ningrum, I. P., \& Yamin, M. (2017). Hologram Holographic Pyramid 3 Dimensi. Seman TIK, 3(1), 181-188. 